\title{
Industrial Air Pollution and Its Effects on Human's Respiratory System (A Sociological Study of Bhoun shugar Mill District Jhang, Pakistan)
}

Naveed Gull

Department of Sociology, University of Sargodha,

Dr. Yasir Nawaz

Department of Sociology, University of Sargodha,

Muhammad Ali

Department of Sociology, University of Agriculture, DG khan Campus

Dr. Nisar Hussain

Department of Agri.Ext. College of Agriculture, DG khan,

Rab Nawaz

Department of Sociology, University of Sargodha,

Shahzad Khaver Mushtaq

Department of Sociology, University of Sargodha

Doi:10.5901/ajis.2013.v2n3p535

\section{Abstract}

This research explores the phenomenon of the awareness of people about industrial air pollution and its effects on human's respiratory system. It is a comparative study in Bhoun Shugar mill Jhang. There were two universes for the present research one who were living in industry and the other who were living near villages industry. The researchers selected 90 respondents by using purposive sampling technique. The tool of data collection for Survey was a semi structured interview schedule, constructed in English. Interview schedule was comprised of 24 questions. There were 6 themes in focus group discussion guide. The data was collected, tabulated and analyzed. Chi- square test is used and percentages calculated for the analysis of data, which were indicating that those people who lived near industrial area were affected more due to industrial air pollution than those who lived far away from industries. Results illustrated that majority of the respondents (91.1 percent) were aware about reasons of air pollution in their area. However, 88.9 percent respondents were aware about the effects of industrial air pollution. Greater part of respondents (90.0 percent) faced respiratory health problems due to industrial smoke. Majority of respondents (83.3 percent) felt hurdles in their routine work and social life due to industrial smoke.

\section{Introduction}

This study explores the trend of the effects of industrial air pollution on human being respiratory structure. The man and this universe have been made for some purpose, which is to set a balance and symmetry in the world. All the things around us such as plants, water, air, animals, etc. make our environment. The relationship between human and his environment is a two way process. If one is disturbed, other will automatically be the victim.

The present study is conducted to check the awareness about the industrial air pollution among the people living besides the industries and to illustrate the effects of ill-environment on the health of human beings regarding their respiratory system. As it is an admitted fact that the environment provides man with the essential life-support systems, which comprises air, water and land. On the other hand it also gives him a variety of hazards, which may prejudice his 
health. Its other purpose is to conduct it in a non industrial area to check the presence and non-presence of the industrial air pollution and respiratory diseases. For this purpose a comparative study is conducted within two areas of Jhang city. One having the Cane (Shugar mil) industry Bhoun, Sargodha road Jhang) and other was the non industrial area (Dhoriwala, Sargodha road Jhang) on a little distance from the former area.

\subsection{Health}

The WHO has defined, "Health is a state of complete physical, mental and social well-being and not merely the absence of disease or infirmity" (WHO, 2008). The World Health Organization (WHO) recognizes that Health is the fundamental right of every human being without distinction of race, religion, and political belief, economic and social conditions (environment) while on the other side the situation is totally opposite of this concept. But unluckily it is provided to some particular group of the society having the best life chances.

Health has direct relation to environment if the environment is polluted, we can not imagine a person to be healthy. It represents a balanced relationship of the body and mind and complete adjustment to the total environment. Health and disease must be intimately related because if disease did not exist it would be irrelevant to talk of health.

\subsection{Disease}

"Disease is maladjustment or maladaptation in an environment, a reaction for the worse between man and hazards or adverse influences in his external environment." (Chattha, F.Gulraiz, 2006). Disease may be called as an abnormal state of body resulting from harmful effects of industrial processes, injurious substances or accidents. It is interesting to note that health has direct relation to environment and several diseases have a direct relation to environmental management. The environmental components involved in infectious diseases such as malaria, allergy etc. Also many other ailments like asthma and other respiratory diseases are known to be environmental linked.

\subsection{Respiratory system}

It has a vital role in human body. The primary function of respiratory system is to deliver oxygen to all parts of the body along with blood. The respiratory system does this through breathing. Breathing is achieved through the mouth, nose, trachea and lungs. When we breathe, we inhale oxygen and exhale carbon dioxide. This exchange of gases is the respiratory system's means of getting oxygen to the blood. So, we can say that respiratory system plays a major role in human to become healthy or unhealthy. Now if the air will be polluted, we cannot expect a person to be healthy. And in this case a person becomes victim of diseases especially asthma and lung cancer.

\subsection{Asthma}

Asthma is a chronic (long-term) lung disease that burn and narrows the airways. Asthma causes frequent periods of wheezing (a whistling sound when one breathes), chest tightness, shortness of breath, and coughing. The coughing often occurs at night or early in the morning. Asthma affects people of all ages, but it most often starts in childhood. In the United States, more than 22 million people are known to have asthma. Nearly 6 million of these people are children. (nhlbi.nih.gov)

\subsection{Lung cancer}

Lung cancer is one of the top most causes of cancer-related death in men and the second most common in women. Lung cancer is responsible for 1.3 million deaths worldwide annually. The main types of lung cancers consist primarily of small cell lung cancer (SCLC) and non-small cell lung cancer (NSCLC). In 2008, the National Cancer Institute (NCI) estimated in the United States that there were 215,020 new cases and 161, 840 cancer related deaths of SCLC and NSCLC combined. Nowadays industrial air pollution is considered the root cause of lung cancer. Therefore the localities living near the industries are extremely disturbed by industrial air pollution. (rnjournal.com). 


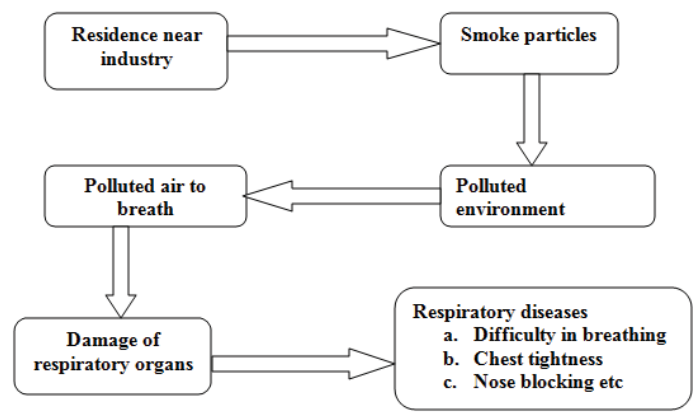

Schematic presentation of industrial air pollution and respiratory diseases

\subsection{Environmental pollution}

Environmental pollution means pollution of the environment due to release of any substance from any process which are capable of causing harms to man and other living organisms supported by environment (Hussain,1998). Rapid industrialization, urbanization and mechanized transport are introducing new and disturbing elements into the environment. A variety of factories, chemical industries, machines are adding to environmental problems and vehicles as well as industrial smoke are causing wide spread respiratory diseases and discomfort (Khan, 1992).

\subsection{Industrial air pollution}

The industrial air pollution first realized as a major problem during the Industrial Revolution in Europe. Industrial pollution is particle especially waste gases like carbon monoxide, sulfur oxides, and nitrogen oxides which are the waste products of industry and end up in the air. Industrial emissions are the second largest pollutants of the atmosphere after automotive exhausts. Industries are the major pollutants. For example petroleum refiners, metal smelting, iron and steel mills, grain mills, and the flour handling industry. These industries create a dangerous environment for the human. The burning of fossil fuels is a major cause of air pollution. Fossil fuels are formed from the remains of ancient plant and animal life such as coal and natural gas.

\subsection{Causes of industrial air pollution}

There are two main causes of air pollution. One of the main causes is natural pollution. Natural pollution is windblown dust, pollen, fog, etc. The other main cause is people pollution or manmade pollution. People pollution is the chief concern and most serious form. Most of people pollution is caused by industry, cars, trucks, and airplanes. The causes of air pollution go on and on. So, keeping in mind the research topic the main focus is put on the industrial air pollution e.g. emissions and the burning of fossil fuels. It was observed by the researchers that the man made pollution is more dangerous to human health as compared to natural pollution. Following are the main causes of industrial air pollution.

Carbon dioxide $\left(\mathrm{CO}_{2}\right)$ is one of the main pollutants that cause industrial air pollution. It is used in various industries such as oil and the chemical as well as in paper industries. A number of specialized production processes in paper industry and petroleum-based products can also lead to $\mathrm{CO}_{2}$ emissions which cause the fatal respiratory diseases. Like carbon dioxide, carbon monoxide ( $\mathrm{CO}$ ) is also produced by incomplete fossil fuel combustion (burning) in industries that pollutes the air that adds to the industrial air pollution.

Sulfur dioxide $\left(\mathrm{SO}_{2}\right)$ is yet another harmful pollutant that causes air pollution. Sulfur dioxide is also the form of industrial air pollution because it is the production of chemical industries. It is emitted largely to the excessive burning of fossil fuels, petroleum refineries, chemical and coal burning power plants etc.

Nitrogen dioxide $\left(\mathrm{NO}_{2}\right)$ is another gas that is emitted into the atmosphere as a result of various human activities. An excess of nitrogen dioxide mainly happens due to most power plants seen in major cities, the burning of fuels due to various motor vehicles and other such sources, as industrial or commercial that cause the increase in the levels of nitrogen dioxide. $\mathrm{NO}_{2}$ is one of the most prominent air pollutants especially with the reference of industries. 


\subsection{Effects of industrial air pollution on human's respiratory system}

The effects of industrial air pollution on the environment are same as any other pollution is harmful to the environment as well as human beings. It is very important to know that industrial air pollution has also no boundary like the air pollution. Because it has no borders so, it travels easily from its sources. It also has been approved by the data collected from the relevant field of this study, as people said that smoke particles fly in the air even falls like snow falling in the houses and in the people being studied. These particles were also seen by the researchers practically, during their visit for data collection in that industrial locality. These pollutants are especially harmful to the human respiratory system. Each day we breathe about 20,000 times. All of this breathing couldn't happen without the help of respiratory system, which includes the nose, throat, voice box, windpipe, and lungs. With each breathe, living beings take in air through nostrils and mouth, and their lungs fill up and empty out. As air is inhaled, the mucous membranes of the nose and mouth warm and dampen the air. Even if the air they breathe is dirty or polluted, their respiratory system filters out foreign matter and organisms that enter through the nose and mouth. One cannot expect to remain healthy living in the polluted air. The respiratory system is by far the most important route for entry of air pollutants into the body and thus becomes their primary target. Respondents also shared their views regarding the problems created because of the pollutants of paper industry like, breathing problems, puffed, as well as nose blocking and chest tightness. They also shared some other problems like, they said that they cannot sleep in open air even they cannot cook their food outside the kitchen. Respondents are also facing financial problems because these pollutants pollute their clothes when they spread them for drying purpose and they have to re-wash them. Due to these dangerous black particles, their fertile land is also being destroyed; even they cannot use pure fodder for their animals like cows and buffalos.

\section{Objectives of the study}

- To determine whether there was a higher incidence of respiratory ill health in human living near the industrial area than in those from a non industrial area.

- To measure the awareness of people towards industrial air pollution.

- To check the disturbance in the functioning of human's respiratory system.

- To check the effects of industrial air pollution on routine life of the people residing near industries.

\section{Sociological Significance}

The topic is very closely related to social aspects, as we know man is a social animal so each and every problem he has to face is known as social problem. The people who live in polluted areas are much disturbed by industrial air pollution and their health is more affected than other peoples, obviously their attitude and behavior also changed. There is also disturbance in their social, economic, psychological and physical patterns of living. They are not well financially as they have to spend a lot of on their diseases. In this way they spend more on illness than their earning. Most of people are living in industrial areas because of labor and illness affects them badly.

So, being sociologists it's our responsibility to check all those factors which become the hurdle in the prosperity of society as well as individual. They have to face many social problems like their crops damaged every year, they drank polluted water, they become restless as industrial smoke irritates them etc. This study is also sociologically significant because it is measuring through the people's behavior and researchers try to know how much residents aware all this phenomena. Being aware of social phenomena is also checked. They protested against industrial smoke and dissatisfied with the present situation in Bhoun shugar mil district Jhang. Moreover this study will draw the attention of social as well as environmental agencies towards this social problem which is affecting the all aspects of social life of residents of that particular area. Industrial air pollution has become a great problem for the people of big cities and to think over for its solutions is a sociological exercise and as such falls in the realms of sociology.

\section{Literature Review}

A study conducted by University of North Carolina (2000) researchers determined that individuals living near a factory experienced increased occurrences of headaches, runny noses, sore throats, excessive coughing, diarrhea, and burning eyes than those living in areas without any industrial operations.

Dr. Charles Aston (2001) in the study conducted in Europe by EPA identified through a questionnaire that the dust 
and unhealthy air in factory area was a major factor in the high incidence of tuberculosis, bronchitis and asthma amongst residents. The result is difficulty of breathing, asthma, etc.

H. Janaka de Silva et al., (2002) conducted a cross-sectional comparative prevalence study to evaluate the effect of air pollution on individuals who lived in an industrial zone in Sri Lanka. Moreover, they compare the individuals who are living in non-industrial zone. The authors used a pretest questionnaire. In their research, they concluded that children in the industrial area were 2.3 times more likely to have respiratory infections like coughing and asthma and the adult population was 2.1 times more likely to have these respiratory infections such as asthma and lung cancer than the people who are living in non-industrial zone.

E.E. Nkwocha \& R.O. Egejuru (2004) calculated the effects of industrial air pollution on the respiratory health of children in Nigeria. 250 children were sampled from six primary schools for the period of 18 months. Subjects were divided into two zones A \& B. Monitored and examined on weekly basis. The effect of four criteria pollutants (Nitrogen dioxide, Sculpture dioxide, particulate matter and carbon monoxide) on the respiratory health of children and diseases were also examined such as cough, cold, bronchitis, asthma and lung cancer. Data was obtained from survey method. Results showed that there was a strong association between industrial air pollution and symptoms of diseases among children. The effect was strongest among children below two years of age in the high polluted than in the less polluted area.

The most recent study conducted by Pakistan EPA and the World Bank (2006) on "the impact of industrial air pollution on human health" resulted that it causes 22,000 premature deaths in adults and 700 in children annually. In terms of annual Disability Adjusted Life Years lost, mortality accounted for an estimated 60 percent followed by respiratory symptoms.

\section{Methodology}

As the present study is comparative so researchers have two universes one is residential area of Industries and other is non industrial residential area. It includes all the population of industrial residential area of Bhoun shugar mill district Jhang and non industrial residential area of Jhang Sargodha road.

Sample refers to the complete group of people, that is being study and that will depend on the testimonial or hypothesis, the researchers desire to explore in the research.

The researchers selected the sample of 90 respondents from the residential areas of Bhoun Shugar mill village near the rise processing mills. Household's member (age of 20 to 50) is taken for the sample. For other universe researchers selected the forty individuals for focus group discussion from village Dhoriwala (age of 20 to 50).

The first population has been targeted for the following reasons:

1. The people living in the industry have more chances of being effected by industrial smoke.

2. They are directly influenced by the industries.

3. They have more chances of becoming the victim of respiratory diseases.

4. They protested again and again against Industries which became the cause of industrial air pollution.

The second population has been targeted for the following reasons:

1. As they live far away from the industries that is why they are not more exposed to industrial air pollution.

2. They have no more chances of respiratory diseases due to industrial air pollution.

\subsection{Sampling technique}

Sampling technique facilitates the researchers to attain the adequate and required information from a reasonably few cases that be a symbol of all the characteristics of the overall population. It gives competence, reliability and accuracy to the result in less time and expenditures.

Careful sampling method means that often the information presented by the sample can be overviewed and generalized with great accuracy to the whole population under study. For that reason, the researchers adopt the purposive sampling method to draw the sample from the whole population.

\subsection{Research Design \& Research Techniques}

The researchers used both qualitative and quantitative research designs in their study. The basic intention behind using both research designs was to make study more reliable and valid from scientific research point of view. As researchers 
could not conduct research only in one area but for supporting their study took two populations and show comparison so that their study will be more valid. The two different research techniques according to the research designs were used in the present study. For qualitative research design focus group discussion technique and for quantitative research design survey was used by the researchers.

\section{Findings and Analysis}

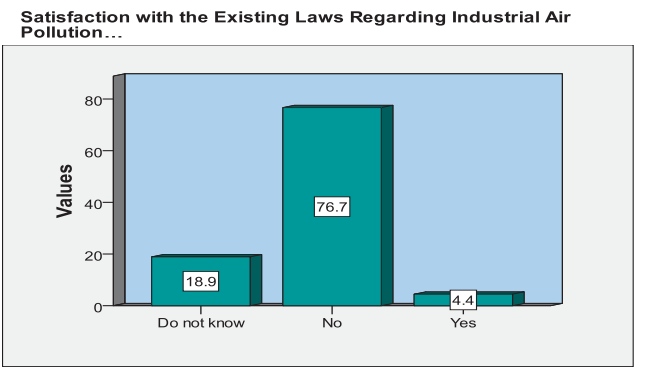

\subsection{Testing of the hypothesis:}

It is a procedure in which researchers decide on the basis of responses obtained from sample data whether to accept or reject statement or an assumption in the form of hypothesis about the value of parameter.

The hypothesis which is formulated for the present study is.

"More the industrial air pollution, more will be the chances of respiratory diseases"

$\mathrm{H} 1$ : There is an association between industrial air pollution and the respiratory diseases.

Ho: There is no association between industrial air pollution and the respiratory diseases.

Level of significance $a=0.05$

Level of confidence $=.95$ or $95 \%$

\subsubsection{Applying Chi -square test}

Chi square test is being applied to find out the relationship between these two variables.

$$
\mathbf{X}^{2}=\frac{\sum(\mathbf{f o}-\mathrm{fe})^{2}}{\mathbf{f e}}
$$

\subsubsection{Why Chi -square}

Because independent variable "effect of industrial air pollution on adjacent locality" is ordinal level data and dependent variable "respiratory health problems due to industrial air pollution" is nominal nature of data, so in this case Chi -square is the most suitable test to find out the relationship between these two variables.

\subsubsection{Cross tabulation}

Effects of Industrial air pollution on the respiratory health Problems

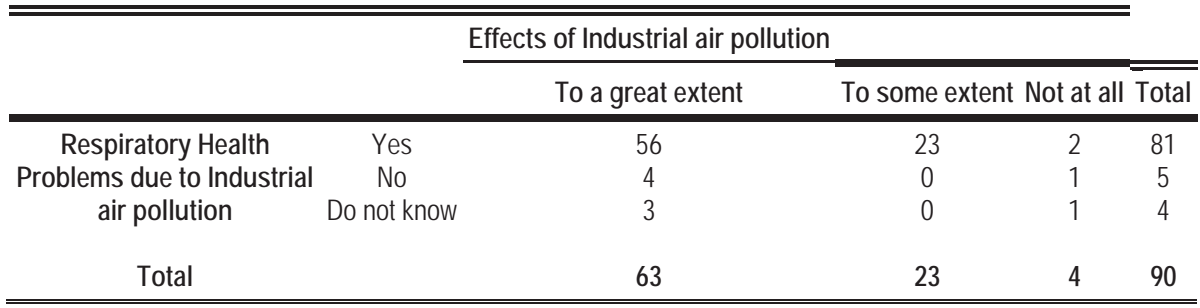




\section{Symmetric Measures}

\begin{tabular}{lccc}
\hline \hline & & Value & Approx. Sig. \\
\hline Nominal by Nominal & Phi & .331 & .042 \\
& Cramer's V & .234 & .042 \\
No. of Valid Cases & & 90 & \\
\hline \hline
\end{tabular}

P- Value $=.042<0.05$

$X^{2}$ value $=9.886$

P-value $=.042$

\subsubsection{Conclusion}

The above mentioned table indicates that p-value is .042 and the level of significance is 0.05 . As P-value is less than alpha $(0.05)$ therefore null hypothesis $\left(\mathrm{H}_{0}\right)$ is rejected and alternative hypothesis $\left(\mathrm{H}_{1}\right)$ is accepted. If we reject the null hypothesis, we will be wrong 5 times and will commit type one error. Type one error is denoted by $\beta$. And the type one error is that we reject the null hypothesis when actually it is true. So we can conclude that there is a significant relationship between these two variables and both are not independent variables. In other words we can say "more the industrial air pollution more will be the chances of respiratory diseases".

After accepting the alternative hypothesis the next step is to find out the degree of association between these two variables. Cross table shows that it is a $3 * 3$ table and in this situation we will use the value of Cramer's V which is .234. This value shows that there is a weak association between industrial air pollution and the respiratory diseases.

\subsection{Test 2:}

Ho: There is no association between effects of industrial smoke on adjacent locality and the health problems due to industrial smoke

$\mathrm{H1}$ : There is an association between effects of industrial smoke on adjacent locality and the health problems due to industrial smoke

Level of significance $a=0.05$

Level of confidence $=.95$ or $95 \%$

\subsubsection{Applying Chi -square test}

Chi square test is being applied to find out the relationship between these two variables.

$$
X^{2}=\frac{\sum(f o-f e)^{2}}{f e}
$$

\subsubsection{Why Chi -square}

Because independent variable "effects of industrial smoke on adjacent locality" is ordinal level data and dependent variable "health problems due to industrial smoke" has a nominal nature of data, so in this case to find out the relationship between these two variables Chi -square is the most suitable test.

Health Problems due to Industrial Smoke * Industrial Smoke effects Adjacent Locality Cross tabulation

\begin{tabular}{|c|c|c|c|c|c|}
\hline \multicolumn{6}{|c|}{ Industrial Smoke effects Adjacent Locality } \\
\hline & & To a great extent & To some extent & Not at all & Total \\
\hline $\begin{array}{l}\text { Health Problems } \\
\text { due to Industrial } \\
\text { Smoke }\end{array}$ & $\begin{array}{c}\text { Yes } \\
\text { No } \\
\text { Do not know }\end{array}$ & $\begin{array}{c}56 \\
4 \\
3\end{array}$ & $\begin{array}{c}23 \\
0 \\
0\end{array}$ & $\begin{array}{l}2 \\
1 \\
1\end{array}$ & $\begin{array}{c}81 \\
5 \\
4\end{array}$ \\
\hline Total & & 63 & 23 & 4 & 90 \\
\hline
\end{tabular}




\section{Symmetric Measures}

\begin{tabular}{lccc}
\hline \hline & & Value & Approx. Sig. \\
\hline Nominal by Nominal & Phi & .331 & .042 \\
& Cramer's V & .234 & .042 \\
No. of Valid Cases & & 90 & \\
\hline \hline
\end{tabular}

P- Value $=.042<0.05$

$X^{2}$ value $=9.886$

P-value $=.042$

\subsubsection{Conclusion}

The above mentioned table indicates that the $p$-value is .042 and the level of significance is 0.05 . Because the $p$-value is less than alpha $(0.05)$ we are able to reject the null hypothesis $\left(\mathrm{H}_{0}\right)$ and are able to accept the alternative hypothesis $\left(\mathrm{H}_{1}\right)$. If we reject the null hypothesis, we will be wrong 5 times and will commit type one error. Type one error is denoted by $\beta$. And the type one error is that we reject the null hypothesis when actually it is true. So we can conclude that there is a significant relationship between these two variables and both are not independent variables. In other words we can say that as much as people will be living near the industries, the industrial smoke will affect their health and people have more health diseases as compared to different location and it is testified by applying the Chi square test.

After accepting the alternative hypothesis the next step is to find out the degree of association between these two variables. Cross tabulation shows that it is a $3 * 3$ table and in this situation we will see the value of Cramer's $V$ which is .234. This value shows that there is a weak association between living the adjacent locality of industries and the facing of health problems.

\subsection{Test 3 :}

Ho:There is no relationship between years of living and feelings of chest tightness.

$\mathrm{H} 1$ : There is relationship between years of living and feelings of chest tightness.

Level of significance $a=0.05$

Level of confidence $=.95$ or $95 \%$

\subsubsection{Applying Chi -square test}

Chi square is the best test of significance to find out the relationship between these two variables.

\subsubsection{Why Chi -square}

$$
\mathbf{X}^{2}=\frac{\sum(\mathbf{f o}-\mathbf{f e})^{2}}{\mathbf{f e}}
$$

In this hypothesis the years of living is taken as an independent variable and the feelings of chest tightness as dependent variable which is the symptom of respiratory diseases. Because both the independent and dependent variables are of ordinal level, so in this condition Chi -square is the most suitable test to find out the relationship between these two variables.

Feelings of Chest Tightness * Years of Living Cross tabulation

\begin{tabular}{|c|c|c|c|c|c|c|}
\hline \multicolumn{7}{|c|}{ Years of Living } \\
\hline & & \multicolumn{5}{|c|}{ More than 30 years 20 to 30 years 10 to 20 years Less than 10 years Total } \\
\hline Feelings of Chest Tightness & To a great extent & 31 & 14 & 11 & 36 & 62 \\
\hline & To some extent & 20 & 2 & 0 & 0 & 22 \\
\hline & Not at all & 3 & 2 & 1 & 0 & 6 \\
\hline Total & & 54 & 18 & 12 & 6 & 90 \\
\hline
\end{tabular}


Symmetric Measures

\begin{tabular}{lccc}
\hline \hline & & Value & Approx. Sig. \\
\hline Nominal by Nominal & Phi & .384 & .039 \\
& Cramer's V & .272 & .039 \\
No. of Valid Cases & & 90 & \\
\hline \hline
\end{tabular}

P- Value $=.039<0.05$

$X^{2}$ value $=13.282$

P-value $=.039$

\subsubsection{Conclusion}

The above cross tabulation shows that the $p$-value is .039 which is less than from level of significance $(0.05)$. Now the $p$ value is less than alpha $(0.05)$ we will reject the null hypothesis $\left(\mathrm{H}_{0}\right)$ and will accept the alternative hypothesis $\left(\mathrm{H}_{1}\right)$. If we reject the null hypothesis, we will be wrong 5 times and will commit type one error denoted by $\beta$. And the type one error is that we reject the null hypothesis when it is supposed to be true. So we can conclude that there is a significant relationship between these two variables, in other words we can say that if a person has been living for a long time in the industrial location, he has more chances of the chest tightness which is one of the indicator to measure the respiratory diseases.

Because our hypothesis is accepted that year of living effects on the chest tightness, we will see the value of Cramer's $V$ for the degree of association. The value of Cramer's V (.272) tells us that there is a weak association between these two variables.

\section{Conclusions}

The study is an attempt to see the awareness of people about industrial air pollution and its effects on human's respiratory system. After conducting the study at hand there are following conclusions:

There is a relationship between the residence in industrial area and respiratory diseases. However, relationship is weak between living near the industries and having health problems due to industrial smoke. Results show that 83.3 percent respondents acknowledged that industrial air pollution is responsible for problems in their respiratory system.

The people who live far away from the industries have less chances of being effected from industrial smoke. As industrial smoke does not play much role to disturb them i.e. psychologically, financially and physically. Industrial smoke is the main reason of industrial air pollution.

Both of the populations (In industrial and non industrial zone) are aware of the effects of industrial smoke. The residents of industrial zone are in front of many health issues but they are not changing their residence due to financial factors.

Respondents highly acknowledged that industrial smoke badly affects their daily life for example they told black smoke emitted from paper industries fall in their houses like snow. They neither sit in their courtyards and nor cook food. They can not dry their clothes in the open air and it is difficult for them to sleep in courtyards.

Moreover, due to black particles their crops are damaging, their houses and roofs have completely become black, their clothes become black and all these become a financial burden for them. Due to health problems they had to go for doctor which also increases their expenditures.

It is also concluded from the research findings that majority of the respondents recognized industrial air pollution plays major role in the illness of respiratory system.

As the respondents are living in deteriorated conditions in Sheikhupura's industrial zone, they protested against this industrial pollution every year. However, no governmental agency took notice of their protest. So, the majority of the respondents both in industrial and non industrial zone are not satisfied with the existing governmental laws of industrial air pollution.

\section{Suggestions}

After conducting the present research, the following are productive suggestions for other researchers.

- The subject related to environmental sociology should be taught in schools, colleges and universities so that 
people may become aware of environmental pollution especially the smoke of industries.

- A sense to make clean the atmosphere should be developed by the electronic and print media among masses.

- Health agencies with the co-operation of the Government should check the health effects of industrial smoke on the communities locating near industries on regular basis.

- Laws should made by EPA to control the chemicals that ruin the air.

- Socio Demographic differences in personal exposure to the industrial smoke can be checked by future researchers.

- This study is conducted on Bhoun shugar mill district Jhang future researchers should also conduct researches in other cities that have more factories like Faisalabad, Gujranwala and Muridke and sheikhupura etc.

- This study only focuses the phenomena of industrial air pollution other researchers can take many other industrial pollutions like water, noise and soil etc to see the effects on human health.

- The present study deals with respiratory system affected by industrial air pollution researchers can check what other diseases generate due to industrial air pollution like bone and eye diseases etc.

- This study will be very useful if conduct only on children to check asthma due to industrial air pollution.

- The impact of industrial smoke can also be checked on the human behavior in Bhoun shugar mill and village as well as in other industrial cities.

\section{References}

Aston.C. (2001). The dust and unhealthy air in factory area was a major factor of tuberculosis, bronchitis, asthma. Environmental Protection Agency. Europe.

Arunasalam.P, Bandula.C, Dissanayake.S, Janaka.J \& Ranjan.P, (2002).A cross-sectional comparative prevalence study to evaluate the effect of air pollution on individuals who lived in an industrial zone and in a non-industrial zone. Archives of Environmental Health: An International Journal, 57(6), 579-583. Sri Lanka. Doi: 10.1080/00039890209602091.

Ashworth.W and Little.F (eds.) Encyclopedia of environmental studies (new.ed, p.10). New York, United States

Bouble .W, Fox .L, Turner.B and Stern A. (2003). Fundamentals of air pollution. (3rd ed.).Victoria, Australia. (p.106).

Baker.S. (2008). A direct link between air pollution and high blood pressure, or hypertension and respiratory diseases. Arteriosclerosis, Thrombosis, and Vascular Biology. New Ohio State, America. Retrieved September 09, 2008.

Bency.T Jansy. J. \& Nair. K. Air pollution related human diseases in Thiruvananthapuram city Kerala. Kerala.

Chattah.F. (2006). The effects of external environment human health, Government college university Faisalabad.

Claussen.B, Madsen.C, Næss.O, Nafstad.P \& Piro.F. Those living within 2 miles of a factory farm reported higher rates of respiratory problems. University of lowa.

Ding.J . (1996). Air pollution is a problem. Taiwan.

Fritz. (2001). Respiratory disease in infancy and childhood has respiratory health consequences in later life by air pollution. Leipzig, Germany

Hussain. C. M. (1998). Environmental Degradation (Realities and Remedies). Published, Feroz Sons (pvt) LTD

Khan. A. (1992). The environment today and its decay. Journal of rural development and administration. Vol: 26: No: 3PP: 114. 172.

Khan.S. (2004). Govt not stopping pollution by Flying Paper Mills. Daily Times. Retrieved September 18, 2004. http://www.dailytimes.com.pk/default.asp.

Malik .A. Call to shift polluting units. http://www.dawn.com/2004/07/07/fea.htm.

Muthukumar P. \& Sundar.I (2002, April 2). Environmental Sociology. (p.33, 57, 59, 76, 77, 78-79,229).

Masood, Shamoona. (1990). Role of education in creating awareness among women about environmental pollution its causes and effects. An unpublished M.A. thesis, Lahore Department of Sociology, University of the Punjab, Pakistan.

Naz.S. (1993).Causes and consequences of industrial pollution: Industrial Perspective. An unpublished M.A. thesis, Lahore Department of Sociology, University of the Punjab, Pakistan.

Neuman. L.W (2006) Social Research Methods: Qualitative and Quantitative approaches. (6 th $^{\text {ed, }}$ p. 412). Rashtriya printers, Delhi, India.

Nkwocha.E.E. \& Egejuru .R.O. (2004).The effects of industrial air pollution on the respiratory health of children in Nigeria. Nigeria.

Pope. T. (2005). Industrial pollution accounts for approximately 50 percent of the pollution. American Environmental Protection Agency. United States.

Rotko. T. (2004). The socio-demographic differences in personal exposure and about air pollution. Department of Sociology University of Helsinki, Helsinki, Finland.

Sichelitides. Y. (2001).The effects of environmental pollution on the respiratory system of children in Western Macedonia Greece. Western Macedonia Greece.

Srivastava. P. (2005). Environmental pollution and its management. (p.7).

Smith. A. (1986). People living near factory area have a lower life expectancy. Chernobyl nuclear reactor, Ukraine. 
Official Records of the World Health Organization, no. 2, p. 100: 7 April 1948

Webster's 3rd New International Dictionary. (1967). Chicago, Illinois, United States. (5 $5^{\text {th }}$ ed, p., 1934).

(2007). Industrial air pollution and respiratory diseases. National Institute of Environmental Health Sciences. United States.

The Oxford English Dictionary. (1989). London, United Kingdom. (2nd.ed, p 23).

(2006). The impact of industrial air pollution on human health. Pakistan EPA \& the World Bank. Lahore, Pakistan.

Chambers Concise Dictionary. (1967). United State. (Deluxe ed, p.1167).

(2004).Impact of industrial air pollution on children's health and development in Europe. World health organization.

(2003). A strong correlation between respiratory related deaths and air pollution from industries. University of Birmingham.

(2002).Possible health disorders related to odorous emissions coming from an industrial park. Israel Ministry of Health.

(2000). individuals living near a factory experienced increased occurrences of runny noses, sore throats, excessive coughing. University of North Carolina.

(1999-2000).Patients near and around particulate matter air pollution had an increased risk of pulmonary diseases and decrease in lung function. University of Washington. United States.

(1999).Industrial air pollution causes numerous health consequences for people. 